\title{
VIOLÊNCIA OBSTÉTRICA: UMA ANÁLISE SOB O PRISMA DA AUTONOMIA, BENEFICÊNCIA E DIGNIDADE DA PESSOA HUMANA
}

\author{
Delmo Mattos da Silva* \\ Maiane Cibele de Mesquita Serra*
}

\section{RESUMO}

A violência obstétrica corresponde a uma forma específica de violência institucional e de gênero e implica em violação de direitos humanos, caracterizada pela imposição de intervenções danosas à integridade física e psicológica das parturientes, perpetrada pelos profissionais de saúde, bem como pelas instituições (públicas e privadas) nas quais tais mulheres são atendidas. O presente estudo tem por objetivo problematizar tal questão a partir da discussão dos princípios bioéticos da autonomia e beneficência, apresentando ainda o princípio da dignidade da pessoa humana como norteador para solução de conflitos entre ambos os princípios.

Palavras-chave: Violência obstétrica. Princípio da autonomia. Princípio da beneficência. Dignidade da pessoa humana. Direitos Humanos.

\section{OBSTETRIC VIOLENCE: AN ANALYSIS THROUGH THE PRISM OF AUTONOMY, BENEFICENCE AND DIGNITY OF THE HUMAN PERSON}

\begin{abstract}
Obstetric violence corresponds to a specific form of institutional and gender violence and it implies violation of human rights, characterized by the imposition of harmful interventions to the physical and psychological integrity of pregnant women, perpetrated by health professionals, as well as by institutions (public and private) in which such women are assisted. This paper has the purpose of discussing the bioethical principles of autonomy and beneficence, presenting the principle of the dignity of the human person as the guiding principle for the solution of conflicts between both principles.
\end{abstract}

Keywords: Obstetric violence. Principle of autonomy. Principle of Beneficence. Dignity of human person. Human rights.

\footnotetext{
* Doutor em Filosofia pela UFRJ. Professor permanente do Programa de Pós-graduação em Meio Ambiente da UniCEUMA. Professor colaborador do Programa de Pós-graduação em Direito e Instituições do Sistema de Justiça da Universidade Federal do Maranhão. Pesquisa FAPEMA e CNPq. Endereço: Rua Cumã, 10, Ed. Pericumã apt 504, Jardim Renascença 2, CEP: 65075700. E mail: delmomattos@hotmail.com

* Mestre em Direito e Instituições do Sistema de Justiça, do Programa de Pós-Graduação em Direito da Universidade Federal do Maranhão (PPGDIR/UFMA). Advogada pela OAB/MA. Endereço: Rua 06, Quadra 28, Casa 35. Cohatrac II. CEP: 65050-000. São Luís - MA. E mail: maianeserra@hotmail.com
}

Revista Brasileira de Direitos e Garantias Fundamentais | e-ISSN: 2526-0111 | Maranhão | v. 3 | n. 2 | p. 42 - 65 | Jul/Dez. 2017. 


\section{INTRODUÇÃO}

A violência é um problema social que está em constante processo de expansão em todas as suas formas. A violência contra a mulher, em especial, é um problema do Estado, uma vez que é uma das violações mais frequentes dos direitos humanos e constitui-se como um problema de saúde pública que gera custos econômicos e sociais elevados. Tal modalidade de violência tem perdurado ao longo da história e na atualidade ganhou caráter endêmico, uma vez que está cotidianamente presente nas comunidades e países de todo o mundo, independentemente da classe social, raça, idade, sexo ou religião. (FONEITE; FEU; MERLO, 2012).

A Organização Mundial de Saúde (OMS) define violência como a imposição de um grau significativo de dor e sofrimento evitáveis. Por sua vez, a violência contra a mulher é definida pela Convenção Interamericana para Prevenir, Punir e Erradicar a Violência contra a Mulher, também conhecida como “Convenção de Belém do Pará”, no seu art. $1^{\circ}$ como: "qualquer ato ou conduta baseada no gênero, que cause morte, dano ou sofrimento físico, sexual ou psicológico à mulher, tanto na esfera pública como na esfera privada”. E no art. $6^{\circ}$ determina que o direito de toda mulher a ser livre de violência, abrange, entre outros, o direito a ser livre de todas as formas de discriminação, além do direito de ser valorizada e educada livre de padrões estereotipados de comportamento e costumes sociais e culturais baseados em conceitos de inferioridade ou subordinação.

No que tange à violência de gênero podemos considerar as violências física, sexual e psicológica ocorridas tanto no âmbito privado quanto público, e podendo ser perpetradas inclusive pelo Estado e seus agentes. Tal tipo de violência manifesta-se por meio das relações de poder, histórica e culturalmente desiguais, ocorridas entre homens e mulheres.

A violência obstétrica, conhecida também como violência institucional na atenção obstétrica corresponde a uma forma específica da violência de gênero, uma vez que há utilização arbitrária do saber por parte de profissionais da saúde no controle dos corpos e da sexualidade das parturientes. Consiste em uma expressão que agrupa as formas de violência e danos originados no cuidado obstétrico profissional, enquadrando-se nesse conceito, todos os atos praticados no corpo da mulher e do neonato sem o devido consentimento.

Revista Brasileira de Direitos e Garantias Fundamentais | e-ISSN: 2526-0111 | Maranhão | v. 3 | n. 2 | p. 42 - 65 | Jul/Dez. 2017. 
Sob essa perspectiva, todo e qualquer procedimento deve ser devidamente informado à parturiente, sendo pautado pelo seu consentimento e tendo como critério bioético o princípio da autonomia que implica em liberdade de escolha. No entanto, esse princípio apresenta-se em uma linha muito tênue com o da beneficência, manifestado através do "não lesar” as pessoas. Nesse sentido, pretende-se discutir a violência obstétrica a partir da exposição do seu conceito normativo e fenomenologia, além de problematizar algumas questões que envolvem a violação a partir dos princípios bioéticos da autonomia e beneficência, atrelando-se tais ponderações ao princípio da dignidade da pessoa humana.

A metodologia utilizada consistiu em uma investigação de caráter exploratório, do tipo qualitativo, envolvendo pesquisa bibliográfica. Este estudo se justifica pela relevância social e jurídica da temática, uma vez que consoante pesquisa realizada pela Fundação Perseu Abramo (VENTURI; GODINHO, 2010), uma em cada quatro mulheres sofre violência obstétrica.

\section{O CONCEITO NORMATIVO DE VIOLÊNCIA OBSTÉTRICA E A SUA FENOMENOLOGIA}

A construção do conceito da violência obstétrica está diretamente relacionada à história do parto, e se fez presente, sobretudo, após a inserção da prática obstétrica na medicina em que o parto deixou de ser um episódio natural, compartilhado apenas no seio familiar, para se tornar uma espécie de evento no ambiente hospitalar, prática dominada pela medicina e institucionalizada nos hospitais. (WOLFF; WALDOW, 2008). Também conhecida como violência institucional na atenção obstétrica, a violência obstétrica abrange momentos distintos, quais sejam, pré-natal, parto, pós-parto e situações de abortamento, podendo ser perpetrada de modo verbal, físico, psicológico ou até mesmo sexual, expressando-se ainda, de modo explícito ou velado. (CIELLO et al, 2012).

O conceito normativo da prática foi adotado pela Venezuela, primeiro país latinoamericano a utilizar a expressão "violência obstétrica” na Lei Orgânica sobre o Direito das 
Mulheres a uma Vida Livre de Violência $^{1}$ promulgada em 16 de março de 2007. Posteriormente o termo "obstetric violence" foi cunhado no meio acadêmico pelo presidente da Sociedade de Obstetrícia e Ginecologia da Venezuela, Dr. Rogelio Pérez D’Gregorio em um editorial online publicado em 6 de outubro de 2010 no International Journal of Gynecology and Obstetrics² ${ }^{2}$, descrevendo as menções específicas da nomenclatura "violência obstétrica" ora citada na lei venezuelana. Desde então, os movimentos feministas passaram a utilizar o termo na luta pela eliminação e punição dos atos e demais procedimentos violentos realizados durante o atendimento e assistência ao parto, em prol da humanização no momento da concepção.

A violência obstétrica corresponde a uma forma específica de violência institucional e de gênero, uma vez que há utilização arbitrária do saber por parte de profissionais da saúde no controle dos corpos e da sexualidade das parturientes. Esta modalidade de violência caracteriza-se pela apropriação do corpo e dos processos reprodutivos da mulher pelos agentes de saúde, mediante um tratamento desumanizado, abuso de medicalização e patologização dos processos naturais, causando a perda de autonomia da parturiente e da capacidade de decidir livremente sobre seu corpo e sexualidade, o que pode culminar em consequências negativas e desastrosas para a qualidade de vida. ${ }^{3}$

Segundo a OMS (2014), muitas das intervenções que são aplicadas rotineiramente são consideradas como um fator de risco tanto para a mulher quanto para o neonato. Ademais, as crenças e os preconceitos no que concerne à sexualidade e saúde das mulheres em uma sociedade tipicamente patriarcal contribuem sobremaneira na forma como elas são percebidas e (des)tratadas pelos profissionais. Ademais, a violência obstétrica é fortemente condicionada por preconceitos de gênero. Consoante Aguiar:

Estes maus tratos vividos pelas pacientes, na maioria das vezes, segundo alguns autores, encontram-se relacionados a práticas discriminatórias por parte dos

1 Texto na íntegra disponível em: <http://venezuela.unfpa.org/sites/lac.unfpa.org/files/pubpdf/Ley_mujer\%20(1)_0.pdf>.

2 Jornal internacional de Ginecologia e Obstetrícia.

${ }^{3}$ Definição dada pelas leis venezuelana e argentina, onde a violência obstétrica é tipificada: Lei Orgânica sobre o Direito das Mulheres a uma Vida Livre de Violência, de novembro de 2007 e Lei Nacional $n^{\circ}$ 26.485, de Proteção Integral para Prevenir, Punir e Erradicar a Violência contra as Mulheres nos Âmbitos em que se Desenvolvem suas Relações Interpessoais, vigente na Argentina desde 2009, respectivamente.

Revista Brasileira de Direitos e Garantias Fundamentais | e-ISSN: 2526-0111 | Maranhão | v. 3 | n. 2 | p. 42 - 65 | Jul/Dez. 2017. 
profissionais, quanto a gênero, entrelaçados com discriminação de classe social e etnia, subjacentes à permanência de uma ideologia que naturaliza a condição social de reprodutora da mulher como seu destino biológico, e marca uma inferioridade física e moral da mulher que permite que seu corpo e sua sexualidade sejam objetos de controle da sociedade através da prática médica. (2010, p. 15).

No segundo semestre de 2014, a OMS se pronunciou a respeito da temática, publicando em seis idiomas uma declaração acerca da violência obstétrica, exigindo políticas e promoção à assistência obstétrica humanizada, além da adoção de medidas governamentais no sentido de abolir o desrespeito e abuso contra as mulheres durante o parto. Segundo a Organização:

Todas as mulheres têm direito ao mais alto padrão de saúde atingível, incluindo o direito a uma assistência digna e respeitosa durante toda a gravidez e o parto, assim como o direito de estar livre da violência e discriminação. Os abusos, os maustratos, a negligência e o desrespeito durante o parto equivalem a uma violação dos direitos humanos fundamentais das mulheres, como descrevem as normas e princípios de direitos humanos adotados internacionalmente. Em especial, as mulheres grávidas têm o direito de serem iguais em dignidade, de serem livres para procurar, receber e dar informações, de não sofrerem discriminações e de usufruírem do mais alto padrão de saúde física e mental, incluindo a saúde sexual e reprodutiva. (2014, p. 1-2).

O conceito de violência obstétrica enquanto violência institucional é entrelaçado com as representações de gênero, tendo em vista que embora as relações desiguais de poder envolvam médicos e pacientes, as parturientes são negligenciadas como sujeitos de direitos, principalmente no contexto sexual e reprodutivo, uma vez que há uma relação hierárquica na qual a paciente é tratada como um objeto de intervenção profissional.

A violência institucional decorre das relações sociais marcadas pelo descaso com os aspectos humanísticos do cuidado, da rigidez hierárquica nas relações dos profissionais de saúde com os pacientes/clientes, das falhas no processo de comunicação, da mecanização do cuidado, do uso inadequado da tecnologia, do não compromisso dos profissionais com o processo de cuidar. (SOUZA, 2014, p. 42).

A violência institucional é exercida tanto no âmbito público quanto privado, por ação ou omissão e inclui desde a dimensão mais ampla relacionada a falta de acesso à saúde, até a má qualidade dos serviços, compreendendo ainda, os abusos cometidos em virtude das 
relações de poder desiguais entre usuários e profissionais dentro das instituições. Esta violência pode ser identificada de várias formas: peregrinação por diversos serviços até receber atendimento; falta de escuta e tempo para a clientela; frieza, rispidez, falta de atenção, negligência; maus-tratos dos profissionais para com os usuários, motivados por discriminação; violação dos direitos reprodutivos; desqualificação do saber prático, da experiência de vida, diante do saber científico; violência física; detrimento das necessidades e direitos da clientela; proibição de acompanhantes ou visitas com horários rígidos ou restritos; críticas ou agressões a quem grita ou expressa dor e desespero, ao invés de se promover uma aproximação e escuta atenciosa visando acalmar a pessoa, fornecendo informações e, buscando condições que lhe tragam maior segurança do atendimento ou durante a internação; diagnósticos imprecisos, acompanhados de prescrição de medicamentos inapropriados ou ineficazes, desprezando ou mascarando os efeitos da violência (BRASIL, 2001).

A violência institucional nos serviços de saúde se caracteriza por sua invisibilidade e por uma aceitação social como uma violência "natural" e justificável, uma vez que as violações dos direitos das mulheres à sua integridade corporal e à sua condição de pessoa são consideradas irrelevantes ou mesmo necessárias, praticadas para o "bem" das mulheres. (DINIZ, 2006). Na atenção obstétrica, essa integridade é constantemente vilipendiada em prol do bem-estar dos bebês.

Nesse sentido, Diniz (2006) aponta que as instituições de saúde frequentemente "sinergizam" várias formas de opressão, reproduzindo comportamentos e rotinas discriminatórias, sem que consigam reconhecer o conteúdo opressor inerente a tais procedimentos. Isso é especialmente verdadeiro nas ações de saúde, onde as rotinas técnicas, de tão repetidas, se "descolam” de sua finalidade original, parecendo neutras aos seus agentes, não sendo observadas como recursos que podem limitar, promover ou violar os direitos das parturientes, a exemplo, as cesáreas eletivas e as episiotomias de rotina.

As categorias de abusos diante da violência obstétrica podem ser sintetizadas da seguinte forma: negligência na assistência, violência verbal, violência física e violência sexual (D’Oliveira et al, 2002), adiciona-se ainda a violência psicológica dada a potencialidade dos danos iatrogênicos oriundos. A partir do panfleto expositivo organizado pela Defensoria 
Pública do Estado de São Paulo (2013) sobre a violência obstétrica, bem como a literatura utilizada no decorrer deste estudo, elaborou-se a síntese abaixo.

$\mathrm{Na}$ negligência os danos iatrogênicos correlacionados referem-se a: abandono, negligência ou recusa de atendimento às mulheres que são percebidas como queixosas, descompensadas ou demandantes; negativa ou demora no atendimento à mulher em situação de abortamento; recusa da admissão em hospital ou maternidade (peregrinação por leito).

O abuso físico correspondente aos procedimentos que indicam sobre o corpo da mulher, que interfiram, causem dor ou dano físico (de grau leve a intenso), tais como: episiotomia ${ }^{4}$ sem necessidade clínica, manobra de Kristeller ${ }^{5}$, cesáreas eletivas ${ }^{6}$, exames de toque sucessivos, dolorosos e realizados por diferentes pessoas, soro com ocitocina ${ }^{7}$ para acelerar o trabalho de parto, privação de alimentos e bebidas, imobilização de braços e pernas (uso de algemas nos casos das presas parturientes), restrição da posição para o parto, intervenções sem anestesia, descolamento de membrana e/ou ruptura artificial da bolsa sem consentimento da mulher, "ponto do marido” (sutura da episiotomia maior que a necessária para fechar o corte a fim de estreitar a vagina e oferecer maior prazer sexual ao parceiro), uso de fórceps sem indicação clínica, tricotomia (raspagem obrigatória dos pelos pubianos), enema (lavagem intestinal), manobra de Valsalva (orientar a mulher a "trincar os dentes e fazer força); mulheres e/ou bebês que ficam retidos em estabelecimentos de saúde até que se

\footnotetext{
${ }^{4}$ Procedimento cirúrgico para aumentar a abertura do canal vaginal, cortando a entrada da vagina com uma tesoura ou bisturi, algumas vezes sem anestesia a fim de facilitar a saída do bebê no momento do parto.

${ }^{5}$ Manobra na parte superior do útero, durante as contrações do parto, visando empurrar o nascituro em direção à pelve a fim de acelerar o trabalho de parto. A OMS classifica a prática como ineficaz, sem evidência científica para utilização e usada de forma inadequada.

${ }^{6}$ A cesárea eletiva é aquela realizada sem necessidade clínica, podendo ser agendada e feita conforme a conveniência médica, antes mesmo do início do trabalho de parto, dissuadindo muitas vezes a mulher quanto à sua necessidade e também a coagindo.

${ }^{7}$ A ocitocina é um hormônio que acelera o processo de contrações uterinas acelerando o trabalho de parto, entretanto, o próprio corpo se encarrega de produzi-lo. A ocitocina sintética (artificial) usada de maneira indiscriminada, apenas para acelerar o trabalho de parto, sem indicação correta e aplicada no soro da parturiente causa o aumento significativo das dores durante as contrações e, se não for controlada pode causar sérias complicações para à mulher e o neonato, podendo levar desde a dor e sofrimento desnecessários ao aumento excessivo da frequência cardíaca da parturiente, além de causar dificuldades na oxigenação do bebê, bem como dano cerebral ao mesmo.
} 
resolva pendências com plano de saúde ou questões relacionadas ao pagamento; impedimento ou retardo no contato da mulher com o bebê após o parto.

O abuso verbal refere-se ao tratamento verbal de modo grosseiro, humilhante, brusco, antipático, áspero, repreensivo, ameaçador, uso de frases jocosas, xingamentos e insultos ridicularizando e humilhando a mulher. Além disso, nos serviços de aborto, as mulheres podem ser verbalmente abusadas, estigmatizadas e ter sua moral questionada.

O abuso sexual refere-se as ações que destinam-se ao controle da sexualidade da mulher através do abuso da posição de poder e confiança, como assédio sexual, flerte, “cantadas”, contatos físicos forçados, convites impertinentes, insinuações, incitações sexuais, mutilação da vagina, exames de toque sucessivos, dolorosos e realizados por diferentes pessoas, episiotomia, ponto do marido, laqueaduras ou histerectomias sem aviso prévio, sem esclarecimento e sem consentimento.

E o abuso psicológico que representa qualquer conduta que cause dano emocional ou prejuízo à saúde psicológica e à autodeterminação da mulher; diminuição, prejuízo ou perturbação ao seu pleno desenvolvimento; que tenha o objetivo de degradá-la ou controlar suas ações, comportamentos, crenças e decisões mediante ameaça, constrangimento, humilhação, manipulação, isolamento, vigilância constante, perseguição, insulto, chantagem, ridicularização, exploração, limitação do direito de ir e vir ou qualquer outro meio, qualquer tipo de discriminação em virtude da raça, etnia, idioma, histórico médico, crenças, preferências, estado civil ou situação conjugal, orientação sexual, número de filhos, status econômico e nível educacional da mulher; proibição injustificada de acompanhante ou autorização apenas para acompanhantes do sexo feminino, questionamento à mulher quando à causa do abortamento (se intencional ou não); ameaça, acusação e culpabilização da mulher nos casos de abortamento; coação com finalidade de confissão e denúncia à polícia.

Todas as formas elencadas impedem a mulher de exercer sua autonomia no processo do seu próprio parto e configuram a violência obstétrica. Bowser e Hill (2010) citam potenciais contribuintes para o desrespeito e o abuso no parto, tais como: a normalização de condutas inapropriadas envolvendo desrespeito e abuso durante o parto; falta de engajamento e fiscalização da comunidade; condições financeiras da mulher e da sua família; falta de autonomia e capacitação das mulheres. D’oliveira et al (2002) enfatizam que a violência

Revista Brasileira de Direitos e Garantias Fundamentais | e-ISSN: 2526-0111 | Maranhão | v. 3 | n. 2 | p. 42 - 65 | Jul/Dez. 2017. 
institucional na atenção obstétrica é invisível ou aceita socialmente como natural, pois é justificada como sendo pertinentes a “práticas necessárias ao bem das próprias mulheres”.

De acordo com Diniz et al (2015), a modalidade de violência tem implicações sobre a morbimortalidade materna das seguintes formas: a. risco adicional associado aos eventos adversos inapropriados durante o parto normal, tais como o recurso não regulado de ocitocina para indução ou aceleração do parto, manobra de Kristeller, fórceps, episiotomia, dentre outras intervenções invasivas e potencialmente danosas; b. em um parto agressivo como forma de constrangimento e coerção para possível realização de uma cesárea; c. na negligência no atendimento às parturientes que expressam seu sofrimento (por meio de choros, gritos e gemidos), que pedem ajuda de modo insistente ou que desejam serem atendidas com urgência; d. na hostilidade contra profissionais de saúde e mulheres dissidentes quanto ao modelo hegemônico de assistência; e. na hostilidade, negligência e retardo no atendimento das mulheres em situação de abortamento; f. no impedimento da presença do acompanhante, o que ameaça contundentemente a segurança da mulher nas situações de violações dos seus direitos.

Nesse sentido, é imprescindível que as práticas obstétricas estejam de acordo com os níveis aceitáveis de interferência no corpo e saúde das gestantes, incluindo as intervenções físicas praticadas pelos profissionais de saúde na atenção obstétrica de forma a prevenir a ocorrência de potenciais danos à saúde e vida das parturientes. Desta forma, tomando por base a violência obstétrica como uma violação dos direitos humanos e constitucionais, pretende-se problematizar o fenômeno como violação da dignidade da pessoa humana, princípio basilar do ordenamento jurídico brasileiro e os princípios bioéticos da autonomia e beneficência.

\section{VIOLÊNCIA OBSTÉTRICA, DIGNIDADE DA PESSOA HUMANA E OS PRINCÍPIOS BIOÉTICOS}

A bioética pode ser compreendida como o estudo sistemático da conduta humana na área das ciências da vida e dos cuidados da saúde, na medida em que esta conduta é examinada à luz dos valores e princípios morais a fim de se conseguir um atendimento eficaz com relação aos problemas da vida, saúde e morte do ser humano. (LEPARGNEUR, 1996). 
Para Ferreira (1998), a bioética seria a ética das biociências e biotecnologias que visa preservar a dignidade, os princípios e valores morais das condutas humanas, meios e fins defensivos e protetivos da vida, em suas várias formas, notadamente, a vida humana e a do planeta.

A teoria principialista ou principialismo configurou-se como instrumento norteador no que tange aos dilemas éticos advindos das pesquisas científicas e sua aplicabilidade, sendo embasado por quatro pilares ou princípios: autonomia, beneficência, não maleficência e justiça. O princípio da autonomia estabelece que o indivíduo deve ter condições de exercer a sua liberdade de escolha sem qualquer forma de coerção. A beneficência destina-se à condição de agir em prol do benefício dos indivíduos, de modo a fazer-lhe o bem. O princípio da maleficência preconiza o dever de não causar dano a alguém. E a justiça baseia-se na noção de tratar cada pessoa de forma adequada. (BEAUCHAMPS; CHILDRESS, 2002).

Além disso, a homologação da Declaração Universal sobre Bioética e Direitos Humanos $^{8}$ (DUBDH) pela Organização das Nações Unidas para a Educação, a Ciência e a Cultura (UNESCO) em 2005 representou o marco conceitual da Bioética, ao tratar das questões éticas suscitadas pela medicina, ciências da vida e tecnologias associadas na sua aplicação aos seres humanos, a declaração incorporou os princípios que norteiam o respeito pela dignidade da pessoa humana, direitos humanos e liberdades fundamentais. Não obstante, serem de grande importância todos os princípios bioéticos apresentados, no presente trabalho enfoca-se os princípios da autonomia versus beneficência, tendo em vista a linha tênue entre eles nas práticas atreladas a violência obstétrica.

Conforme o art. $5^{\circ}$ da DUBDH, a autonomia das pessoas na tomada de decisões de ser respeitada desde que estas assumam a respectiva responsabilidade e respeitem a autonomia dos outros. Segundo tal princípio todas as pessoas ${ }^{9}$ possuem capacidade para

\footnotetext{
${ }^{8}$ A declaração é composta por 15 princípios complementares e inter-relacionados: dignidade humana e direitos humanos, efeitos benéficos e efeitos nocivos, autonomia e responsabilidade individual, consentimento, pessoas incapazes de exprimir o seu consentimento, respeito pela vulnerabilidade humana e integridade pessoal, vida privada e confidencialidade, igualdade, justiça e equidade, não discriminação e não estigmatização, respeito pela diversidade cultural e do pluralismo, solidariedade e cooperação, responsabilidade social e saúde, partilha dos benefícios, proteção das gerações futuras e proteção do meio ambiente, da biosfera e da biodiversidade.

${ }^{9}$ Exceto aquelas incapazes que por alguma razão não podem exprimir a sua vontade, razão pela qual o art. $7^{\circ} \mathrm{da}$ DUBDH concede à estas proteção especial.
} 
determinar o seu próprio destino, tendo, portanto, o direito de agir livremente conforme sua própria consciência e valores morais. No entanto, a autonomia individual está sujeita a várias regras éticas, morais, culturais e religiosas impostas pela sociedade, desde que estas sejam reconhecidas como legítimas pelo indivíduo. (WANSSA, 2011).

Sob essa perspectiva, diante da necessidade de promover a autonomia do paciente, cabe ao médico prover a informação. Nesse sentido, o direito à informação atrela-se ao princípio da autonomia, uma vez que somente com a informação clara acerca dos procedimentos que serão realizados, o paciente é capaz de realizar escolhas autônomas. Desta forma, em nenhuma hipótese, pode o profissional de saúde persuadir o paciente a aceitar um determinado tratamento com o qual não concorde, através de coação, assim, o grau de entendimento e liberdade de coerção são fatores preponderantes na tomada de decisão. Tal princípio é costumeiramente violado nas práticas de violência obstétrica conforme se depreende através do depoimento abaixo:

Quando eu ouvi ele pedindo o bisturi, meu Deus, quase morri! Eu pedi para que não fizesse a episio, mas ele me respondeu: 'O seguro morreu de velho. Quem manda aqui sou eu. (MOURA apud CIELLO et al, 2012, p. 83) ${ }^{10}$

A episisotomia consiste em um procedimento cirúrgico realizado pelos médicos para aumentar a abertura do canal vaginal com uma incisão realizada na vulva, cortando a entrada da vagina com uma tesoura ou bisturi, algumas vezes sem anestesia. A cirurgia afeta diversas estruturas do períneo, tais como os músculos, vasos sanguíneos e tendões, gerando em alguns casos, posterior incontinência urinária e fecal na mulher, além de provocar outras complicações, dentre elas a dor nas relações sexuais, risco de infecção e laceração perineal em partos subsequentes, maior volume de sangramento durante o período menstrual, além dos resultados estéticos insatisfatórios. (PREVIATTI; SOUZA, 2007). Diante do cenário, Previatti e Souza postulam que:

\footnotetext{
${ }^{10}$ A parturiente procurou informações sobre episiotomia durante a gestação e decidiu por não se submeter ao procedimento e comunicou ao médico sobre a decisão. Atendida através de plano de saúde em Belém-PA.
} 
É fato que a episiotomia vem sendo utilizada de forma indiscriminada na assistência obstétrica. É fato também que, os profissionais de saúde arraigados a conceitos e práticas que não contemplam os resultados de evidências científicas atuais, bem como, as práticas baseadas nos direitos das mulheres, insistem na realização deste procedimento, mantêm um enfoque intervencionista e assim subtraem da mulherparturiente a possibilidade de experienciar o parto, como um processo fisiológico e fortalecedor de sua autonomia. (2007, p. 198).

A episiotomia ${ }^{11}$ é a única cirurgia do Brasil, realizada sem o consentimento da paciente e sem tampouco a informação sobre os riscos, possíveis benefícios e efeitos adversos, contrariando os preceitos da Medicina Baseada em Evidências (BEM) (CIELLO et al, 2012) e vilipendiando os direitos da parturiente, uma vez que como todo procedimento cirúrgico, a episiotomia só deveria ser realizada com o consentimento pós-informação da paciente, sendo portanto considerada uma mutilação genital feminina. (AMORIM; KATZ, 2008). Conforme Diniz (2003) o uso indevido da episiotomia e da posterior costura (episiorrafia) é um exemplo de violação do direito humano de estar livre de tratamentos cruéis, humilhantes e degradantes e constitui um exemplo típico de apropriação ao corpo da mulher e desrespeito ao seu direito de informação, vilipendiando ainda o princípio da autonomia.

O desconhecimento evidenciado por essas mulheres reforça, por um lado, o poder do profissional de saúde e, por outro, a exclusão da parturiente do ato decisório. O que mais surpreende é que, tida como objeto do cuidado, ela não participa das decisões sobre seu próprio corpo, pois é considerada inabilitada para dar conta da complexidade dos cuidados que necessita, restando-lhe resignar-se com o que lhe é oferecido. (SANTOS; SHIMO, 2008, p. 648).

Conforme Wanssa (2011), a limitação da decisão do paciente no que tange a decisão inteiramente autônoma pode provocar a privação da assistência à saúde e a vontade do paciente, consubstanciada na liberdade, deve ser embasada na informação e na verdade. Nesse

\footnotetext{
${ }^{11}$ A pesquisa Nascer no Brasil estima que a episiotomia seja realizada em 53,5\% dos partos via vaginal no Brasil, enquanto a recomendação da OMS é que seja realizada em $10 \%$ deles. No caso de primíparas, o índice chega a $74 \%$. Na América Latina, as taxas podem atingir de $90 \%$ a $100 \%$ dos casos e apesar de ser uma prática comum no cenário obstétrico, o procedimento foi introduzido na rotina obstétrica sem qualquer evidência científica sobre sua efetividade, razão pela qual se pretende torná-la uma técnica restrita e não mais rotineira em obstetrícia. (ZANETTI et al., 2009; DINIZ, 2001).
}

\section{Revista Brasileira de Direitos e Garantias Fundamentais | e-ISSN: 2526-0111 | Maranhão | v. 3 |}

n. 2 | p. 42 - 65 | Jul/Dez. 2017. 
sentido, muitos profissionais de saúde utilizam informações falaciosas ou coação no intuito de convencer as mulheres a realizar determinados procedimentos, tais como as cesáreas eletivas.

\begin{abstract}
Eu queria muito um parto normal e o meu médico sabia. Ele disse: 'melhor fazer cesárea para não passar da hora, ou você quer colocar a vida do seu filho em risco?'. Eu comecei a chorar e aceitei, lógico! [...] E marcou para a semana antes do natal.” Beatriz, Vitória (ES) ${ }^{12}$ (KONDO et al, 2014b, p. 10).
\end{abstract}

Sob essa perspectiva, Beauchamp e Childress (2002, p. 138), ponderam que o respeito à autonomia requer “O governo pessoal do eu que é livre de inferências controladoras, por parte dos outros, como limitações pessoais que obstam a escolha expressiva da intenção, tais como a compreensão inadequada”. Nesse sentido, conforme observa Mattos et al (2015), a autonomia, nesse sentido, é observada em seu conceito mais puro, baseado na livre escolha do indivíduo, sem qualquer tipo de coerção ou influência externa.

Importante salientar que a cesárea não pode ser vista de modo indiscutível como sinônimo de violência obstétrica, mas pode ser considerada uma prática associada ao fenômeno quando é realizada sem uma real necessidade, ou ainda quando as mulheres passam por um processo de ameaça, coerção e convencimento onde o médico impõe sua vontade, desrespeitando a autonomia da gestante ${ }^{13}$. Além disso, diante da ausência de informação adequada, as parturientes ficam extremamente vulneráveis às indicações de cesáreas, submetendo-se, na maioria dos casos, a uma cirurgia de grande porte com riscos e complicações.

\footnotetext{
${ }^{12}$ Depoimento extraído da cartilha "Violência obstétrica é violência contra a mulher: mulheres em luta pela abolição da violência obstétrica” (KONDO et al, 2014).

${ }^{13}$ Diante dessa problemática, o Conselho Federal de Medicina (CFM) implantou a Resolução 2144/2016 que entrou em vigor no dia 22 de junho de 2016 estabelecendo novos critérios para realização $39^{\mathrm{a}}$ semana de gestação, com o devido registro em prontuário. Conforme a exposição de motivos listados pelo CFM consta como o principal: o respeito a autonomia da parturiente implicando uma reconfiguração na relação médicopaciente. Ao ser bem informada, a mulher deve decidir com o médico as melhores opções de tratamento, reconhecendo-se à paciente, o direito de tomar decisões conscientes, baseadas na melhor evidência científica. Uma vez esclarecido à gestante as vias de parto, riscos e benefícios, a mesma deve externar o seu desejo, mas a decisão tomada deve ser dividida com o médico; e caso não exista concordância, a mulher tem o direito de procurar outro obstetra. Caso a decisão seja pela cesariana, um Termo de Consentimento Livre e Esclarecido que reforce as informações prestadas oralmente e que explique os princípios, as vantagens e desvantagens potenciais da operação deve ser assinado pelo médico e pela paciente.
} 
Diante das ponderações supracitadas, o princípio da beneficência limita-se ao princípio da autonomia em uma linha muito tênue, podendo inclusive ser utilizado como subterfúgio para utilização de procedimentos que segundo os profissionais se não realizados poderiam colocar em risco à vida dos agentes envolvidos. Sob essa perspectiva, Diniz e Guilhem (2012) enfatizam que há uma fronteira tênue entre a proteção e a autoridade, pois muitas vezes em nome da proteção de vulneráveis, pode-se justificar o silenciamento de certas opções discordantes.

O princípio da beneficência resume-se no dever ético de não fazer mal, maximizando os benefícios e minimizando danos e prejuízos, é fazer o que é melhor para o paciente do ponto de vista técnico-profissional e ético, utilizando conhecimentos e habilidades profissionais a serviço do paciente, considerando, na tomada de decisão, a minimização dos riscos e maximização dos benefícios do procedimento que se pretende realizar. (LOCH, 2002).

A questão seria como então assegurar o direito à autonomia a fim de preservar o paciente? Até que ponto o paciente poderia exercer sua autonomia? Para Beauchamp e Childress (2002) o respeito à autonomia significa que a autodeterminação do agente moral só poderá ser considerada quando não produz danos ou sofrimentos a outras pessoas. Muito embora não haja uma hierarquização dos princípios bioéticos, o que se pode verificar nos vinte anos de hegemonia da teoria principialista é o predomínio do princípio da autonomia sobre os demais princípios. (DINIZ E GUILHEM, 2012). Além disso, o apelo ao princípio da autonomia enquanto referência fundamental à mediação de conflitos morais, é fundamental para uma prática reflexiva, uma vez ser este um princípio ético do feminismo anterior à própria entrada na bioética. Importante ainda considerar que muitas vezes o princípio da autonomia pode vir mascarado pela coerção da vontade, a exemplo, o uso e acesso às novas tecnologias reprodutivas, tendo em vista que muitas mulheres se submetem a procedimentos invasivos em virtude dos os papéis hegemônicos atribuídos, em que a maternidade é quase um imperativo social, não exercendo de fato, livremente a autonomia reprodutiva. (DINIZ E GUILHEM, 2012).

Revista Brasileira de Direitos e Garantias Fundamentais | e-ISSN: 2526-0111 | Maranhão | v. 3 | n. 2 | p. 42 - 65 | Jul/Dez. 2017. 


\begin{abstract}
Compreendido desta forma, o conceito de autonomia transforma-se em um perigo, já que elimina a possibilidade de inclusão para as pessoas que não são consideradas plenamente racionais, como é o caso das crianças, mulheres e membros de outros grupos oprimidos. Consequentemente, em vez de contribuir para o efetivo "empoderamento" daqueles em situação de desigualdade, pode, na prática, transformar-se em instrumento de proteção para os privilegiados e tradicionalmente detentores do poder. (DINIZ; GUILHEM, 2012, p. 109-110).
\end{abstract}

Sob esse enfoque, Wanssa (2011) afirma que a beneficência é limitada por obrigações morais, deste modo, os profissionais de saúde não podem exercer o princípio de modo absoluto, havendo uma fronteira deste com a dignidade individual intrínseca a todo ser humano. O problema em torno dessa discussão é paternalismo médico, devendo, portanto, haver um equilíbrio entre a beneficência do médico e a autonomia do paciente no contexto das relações entre ambos.

Na prática, o respeito à autonomia encontra-se em oposição ao modelo paternalista onde todas as decisões são tomadas pelo médico isoladamente, o que impede a atuação do paciente como protagonista do seu próprio tratamento. Sob essa perspectiva, o modelo participativo é considerado ideal do ponto de vista ético, onde o médico utilizando justamente o direito de informação ao paciente, o informa, orienta e aconselha-o, no que tange a tomada de decisões livre e consciente. (UGARTE; ACIOLY, 2014).

\title{
3.1 Dignidade da pessoa humana como princípio comum ao Direito e à Bioética e como parâmetro em questões conflituosas
}

De modo semelhante à Bioética, o Direito também se ocupa da vida, das suas relações com o nascer e o morrer, dos valores, direitos, deveres e responsabilidades que permeiam ambas as fases. Conforme Costa (2000), o Direito é responsável por construir princípios e regras que visam tutelar a dimensão existencial, não patrimonial, mas ligada fundamentalmente à proteção da pessoa, da personalidade humana e do seu atributo específico - a qualidade de "ser humano", isto é, a pessoa humana valorada por si só, pelo exclusivo fato de ser "humana", pessoa em sua irredutível subjetividade e dignidade, dotada de personalidade singular. 
Conforme a Declaração Universal sobre Bioética e Direitos Humanos (2005), a dignidade humana, os direitos humanos e as liberdades fundamentais devem ser plenamente respeitados, devendo os interesses e o bem-estar do indivíduo prevalecer sobre o interesse exclusivo da ciência ou da sociedade. (art. $3^{\circ}$ ). Nesse sentido, a autonomia como valor fundamental das sociedades democráticas representa um dos pilares das conquistas internacionais para a manutenção da dignidade humana. (DINIZ; GUILHEM, 2012).

O princípio da dignidade da pessoa humana, resguardado no art. $1^{0}$, II, da Constituição Federal de 1988, é o fundamento basilar do Estado Democrático de Direito, visto ser um mandado de otimização dos direitos mínimos inerentes a qualquer ser humano, garantindo a efetividade das garantias fundamentais. Segundo Sarlet:

[...] temos por dignidade da pessoa humana a qualidade intrínseca e distintiva de cada ser humano que o faz merecedor do mesmo respeito e consideração por parte do Estado e da comunidade, implicando, neste sentido, um complexo de direitos e deveres fundamentais que assegurem a pessoa tanto contra todo e qualquer ato de cunho degradante e desumano, como venham a lhe garantir as condições existenciais mínimas para uma vida saudável, além de propiciar e promover sua participação ativa e co-responsável nos destinos da própria existência e da vida em comunhão com os demais seres humanos. (2001, p. 60).

Entretanto, a dignidade da pessoa humana, como grande fundamento dos direitos humanos e o foco principal do nosso ordenamento jurídico em que a Carta Magna inspirou a criação de uma gama de direitos fundamentais que se configuram como obrigatórios para a garantia desse fundamento constitucional, no que tange à violência obstétrica, tem sido amplamente desconsiderada, uma vez que os elementos essenciais pertinentes a tal princípio têm sido ignorados.

Conforme Sarlet (et al 2012) o âmbito de proteção do direito a maternidade abarca um conjunto de outros direitos fundamentais, tais como, a saúde, integridade física e psíquica, o direito à vida, todos correlacionados com a dignidade da pessoa humana, formando assim um arcabouço constitucional de proteção a maternidade.

A dignidade é fundamento da autonomia existência da mulher, para além de um fundamento do estado democrático de direito a dignidade da pessoa humana é o princípio que legitima e confere unidade de sentido a toda ordem constitucional, ela significa proteção da pessoa, titular de direitos e deveres, nas relações em que

Revista Brasileira de Direitos e Garantias Fundamentais | e-ISSN: 2526-0111 | Maranhão | v. 3 | n. 2 | p. 42 - 65 | Jul/Dez. 2017. 
participa, mesmo uma relação médico-paciente. A dizer é a dignidade da pessoa humana que serve de mandamento máximo dos outros princípios garantidores dos direitos fundamentais como os sociais. (MARIANI; NASCIMENTO NETO, 2016, p. 10)

Consoante Barroso (2010), a dignidade da pessoa humana abarca três conteúdos essenciais: valor intrínseco, autonomia e valor social da pessoa humana. O valor intrínseco é a posição especial no mundo que distingue o ser humano dos outros seres vivos e das coisas. No plano jurídico, o valor intrínseco da pessoa humana impõe a inviolabilidade da sua dignidade, sendo inerente a uma série de direitos fundamentais: o direito à vida, direito à igualdade, direito à integridade física, além da integridade moral ou psíquica - direitos que têm sido fortemente violados se observados sob a perspectiva da violência obstétrica.

Outro elemento inerente a tal princípio - a autonomia, é o componente ético da dignidade, envolvendo a capacidade de autodeterminação, tendo o indivíduo, o direito de decidir os rumos da própria vida e de desenvolver livremente sua personalidade. "Significa o poder de fazer valorações morais e escolhas existenciais sem imposições externas indevidas [...] Por trás da ideia de autonomia está a de pessoa, de um ser moral consciente, dotado de vontade, livre e responsável”. (BARROSO, 2010, p. 24). A autonomia é outro componente amplamente desrespeitado nas práticas de violência obstétrica, uma vez que a mulher perde a capacidade de decidir livremente sobre seu corpo e sua sexualidade.

O terceiro e último conteúdo - a dignidade como valor comunitário, abarca o elemento social, ou seja, a relação do indivíduo com o grupo, traduzindo a ideia de valores compartilhados pela comunidade, segundo os padrões civilizatórios ou seus ideais de boa vida. Desta forma, o que está em questão não são as escolhas individuais, mas as responsabilidades e deveres a elas associados. Nesse sentido,

A dignidade como valor comunitário destina-se a promover objetivos diversos, dentre os quais se destacam: a) a proteção do próprio indivíduo contra atos autorreferentes; b) a proteção de direitos de terceiros; e c) a proteção de valores sociais, inclusive a solidariedade. (BARROSO, 2010, p. 28) 
A questão preocupante é quando padrões introjetados a uma consciência comunitária, construídos culturalmente, passam a ser utilizados como justificativa para proteção do indivíduo em face de si mesmo, bem como de suas próprias decisões, maquiando, muitas vezes, uma prática injustificável, a exemplo do caso emblemático de violência obstétrica praticado contra Adelir Góes ${ }^{14}$.

Segundo Sarlet (2001), a dignidade da pessoa humana é atingida no momento em que determinada pessoa for descaracterizada ou desconsiderada enquanto sujeito de direitos. Nesse sentido, Beck (apud MATTOS et al, 2015) enfatiza que a consideração do ser humano como um fim em si mesmo, dotado de dignidade, só tem sentido se este for concedido como capaz de autêntica moralidade, e então livre na sua vontade, como pessoa autônoma. Sob essa perspectiva, a dignidade da pessoa humana como princípio jurídico "vai designar não apenas o "ser da pessoa", mas a "humanidade da pessoa"” (COSTA, 2000, p. 161), a compreensão da dimensão e operatividade deste princípio permite o enfretamento jurídico de importantes questões na Bioética, destacando-se nessa perspectiva as conflituosas questões que envolvem a relação entre médico e paciente atreladas à linha tênue que envolve os princípios da autonomia e da beneficência, que podem ser melhor equacionados pela concreção do princípio da dignidade da pessoa humana, desdobrando-se a partir disso, outros princípios constitucionais igualmente importantes, a exemplo do direito à informação, direito à vida, direito à saúde, dentre outros.

\section{CONSIDERAÇÕES FINAIS}

Todas as situações violadoras decorrentes das práticas de violência obstétrica têm efeitos físicos e emocionais significativos na vida das mulheres. Em decorrência das iatrogenias praticadas na seara médica, muitas mulheres morrem, outras carregam para sempre, sequelas físicas e psicológicas. Para que a experiência do parto possa ser de fato prazerosa, não basta que a mulher e o bebê sobrevivam, mas que as garantias de um

\footnotetext{
${ }^{14}$ Enquanto estava em trabalho de parto, Adelir foi levada de casa por policiais com um mandato judicial para o hospital e obrigada a fazer uma cesárea. Adelir estava em sua terceira gravidez e já havia passado por duas cesáreas, queria escolher como ter seu bebê, queria ter autonomia sobre seu corpo, queria decidir o que é melhor para si. Seu marido apoiava sua decisão. Foi impedida. Os médicos e o Estado agiram como se ela fosse incapaz de tomar suas próprias decisões e de arcar com as consequências.
}

Revista Brasileira de Direitos e Garantias Fundamentais | e-ISSN: 2526-0111 | Maranhão | v. 3 | n. 2 | p. 42 - 65 | Jul/Dez. 2017. 
tratamento digno, respeitoso, humanizado e com práticas embasadas em evidências, respeitando-se ainda a autonomia da mulher, sejam levadas em consideração.

Infelizmente, ainda não há instrumentos próprios para identificar e notificar a violência obstétrica, o que colabora para que o problema continue invisibilizado tanto na esfera social quanto jurídica. Ademais, os serviços que funcionam atualmente não encontramse de todo preparados para receber denúncias de violação no tratamento obstétrico.

Por questões culturais, o parto ainda é encarado como um momento de "dor necessária”. Em algumas situações, quando a parturiente se dá conta da violência praticada contra ela, opta pelo silêncio, muitas vezes pelo medo de ser abandonada pelo profissional em um momento onde está altamente vulnerável ou ainda por não se sentir apoiada quanto à denúncia. Outros fatores contribuem ainda para que a mulher violentada não denuncie a prática, a saber, crer que não possui provas suficientes do ato de violência sofrido; desacreditar na justiça e ainda por desconhecer as atitudes que se configuram como violência obstétrica. (PAES, 2015).

Desta forma, a relação desigual entre médico-paciente desdobra-se de modo potencial quando configurada uma violência que conforme Schraiber $(2008,1997)$ na área de saúde é determinada pela crise de confiança na relação médico/paciente, potencializada em virtude da fragilidade dos vínculos de confiança, a despersonalização do cuidado e o predomínio do uso de tecnologia como forma de interação, transformando o paciente em objeto de intervenção.

Desta forma, uma mudança de paradigma implica também na qualidade da dimensão relacional, sendo imprescindível que o profissional desenvolva uma postura mais atenciosa diante do sofrimento do paciente - assim, as relações interpessoais desenvolvidas ao longo da educação formal servirão como experiências emocionais significativas, servindo como lições diante da forma como esses profissionais exercem seu ofício, uma vez que os modelos de comportamentos aos quais os alunos podem estar expostos no ambiente universitário apresentam uma influência significativa sobre a forma futura da atuação profissional, refletindo-se através das atitudes, valores e crenças dos mesmos. (SILVA, 2005). 
Diante das ponderações, segundo Mattos et al (2015) o critério mais correto e seguro na determinação de incidência desta norma constitucional seria obtido através da máxima “ages de forma tal que tome o ser humano sempre como um fim e não como um meio”. Desta forma, "respeitar a autonomia da pessoa implica o reconhecimento da capacidade de todas as pessoas para as próprias decisões, baseadas nos valores pessoais e crenças e a promoção efetiva de condições que favoreçam o exercício dessa autonomia” (MATTOS et al, 2015, p. 48). Nesse sentido, o grande dilema bioético entre a autonomia e beneficência reside no equilíbrio entre ambos os princípios e acima de tudo sendo observando como paradigma norteador, a dignidade da pessoa humana.

\section{REFERÊNCIAS}

AGUIAR, Janaína Marques de. Violência institucional em maternidades públicas: hostilidade ao invés de acolhimento como uma questão de gênero. Disponível em: $<$ http://www.apublica.org/wp-content/uploads/2013/03/JanainaMAguiar.pdf>. Acesso em: 02 nov. 2015.

ARGENTINA. Lei $\mathbf{n}^{\mathbf{0}} \mathbf{2 6 . 4 8 5}$. Ley de protección integral para prevenir, sancionar y erradicar la violencia contra las mujeres en los ámbitos en que desarrollen sus relaciones interpersonales. Abril, 2009. Disponível em:< http://www.cnm.gov.ar/ LegNacional/Ley_26485_decreto_1011.pdf> Acesso em: 16 mar. 2015.

AMORIM, Melania Maria Ramos de; KATZ, Leila. O papel da episiotomia na obstetrícia moderna. Femina, Rio de Janeiro, vol. 36, nº 1, jan. 2008, p. 47-54.

BARROSO, Luís Roberto. A Dignidade da Pessoa Humana no Direito Constitucional Contemporâneo: Natureza Jurídica, Conteúdos Mínimos e Critérios de Aplicação. Versão provisória para debate público. Mimeografado, dezembro de 2010. Disponível em: < http://www.luisrobertobarroso.com.br/wp- content/uploads/ 2010/12/Dignidade_textobase_11dez2010.pdf>. Acesso em: 18 jul. 2016.

BEUACHAMP, Tom L; CHILDRESS, James F.. Princípios de ética biomédica. 4. ed. São Paulo: Loyola, 2002.

BRASIL. Constituição Federal. Vade Mecum Compacto. São Paulo: Saraiva, 2016.

Organização Mundial de Saúde. Prevenção e eliminação de abusos, desrespeito e maus-tratos durante o parto em instituições de saúde. 2014. Disponível em: $<$ http://apps.who.int/iris/bitstream/10665/134588/3/WHO_RHR_14.23 _por.pdf>. Acesso em: 04 nov. 2015.

Revista Brasileira de Direitos e Garantias Fundamentais | e-ISSN: 2526-0111 | Maranhão | v. 3 | n. 2 | p. 42 - 65 | Jul/Dez. 2017. 
Secretaria de Políticas de Saúde. Violência intrafamiliar: orientações para prática em serviço / Secretaria de Políticas de Saúde. - Brasília: Ministério da Saúde, 2001.

BOWSER, Diana; HILL, Kathleen. Exploring evidence for disrespect and abuse in facility-based childbirth: report of a landscape analysis. Bethesda, Maryland: USAIDTRAction Project; 2010.

CIELLO, Cariny et al. Parto do princípio. Mulheres em Rede pela Maternidade Ativa. Dossiê da Violência Obstétrica "Parirás com dor". Disponível em: $<$ https://www.senado.gov.br/comissoes/documentos/SSCEPI/DOC\%20VCM\%20367.pdf>. Acesso em: 10 dez. 2015.

DINIZ, Carmen Simone Grilo. Entre a técnica e os direitos humanos: possibilidades e limites da humanização da assistência ao parto. Tese (doutorado) - Faculdade de Medicina da Universidade de São Paulo. Departamento de Medicina Preventiva. São Paulo, 2001.

DINIZ, Carmen Simone Grilo et al. Abuse and disrespect in childbirth care as a public health issue in Brazil: origins, definitions, impacts on maternal health, and proposals for its prevention. Journal of Human Growth and Development. 2015. 25(3): 377-384. DOI: http://dx.doi.org/10.7322/jhgd.106080

DINIZ, Débora; GUILHEM, Dirce. O que é Bioética. São Paulo: Brasiliense, 2012.

DINIZ, Maria Helena. Curso de Direito Civil Brasileiro: Responsabilidade Civil. 17 ed. São Paulo: Saraiva, 2003.

D’OLIVEIRA, Ana Flávia Pires Lucas; DINIZ, Simone Grilo; SCHRAIBER, Lilia Blima.

Violence against women in health-care institutions: an emerging problem. The Lancet, Vol 359, May 11, 2002. Disponível em:<http://www.thelancet.com/pdfs/journals/lancet/PIIS01406736(02)08592-6.pdf>. Acesso em: 02 nov. 2016.

COSTA, Judith Martins. Bioética e dignidade da pessoa humana: rumo à construção do Biodireito. Revista da Faculdade de Direito da UFRGS, v. 18, 2000.

FERREIRA, Jussara Suzi Assis Borges Nasser. Bioética e biodireito. Scientia luris, Revista do Curso de Mestrado em Direito Negocial, da Universidade Estadual de Londrina, Londrina (PR): (213): 49, 1998/1999.

FONEITE, Josmery; FEO, Alejandra; MERLO, Judith Toro. Grado de conocimiento de violencia obstétrica por el personal de salud. Revista de Obstetricia y Ginecología de Venezuela. v. 72, n.1, Caracas: março, 2012. Disponível em: <http:// 
www.scielo.org.ve/scielo.php?script=sci_arttext\&pid=S004877322012000100002\&lng=es\&n rm=iso\&tlng=es>. Acesso em: 02 nov. 2015.

KONDO, Cristiane Yukiko et al. Episiotomia “é só um cortezinho”: violência obstétrica é violência contra a mulher: mulheres em luta pela abolição da violência obstétrica. 1 ed. São Paulo: Parto do Princípio; Espírito Santo: Fórum de Mulheres do Espírito Santo, 2014a. Disponível em: <http://www.sentidosdonascer.org/wordpress/wp-content/themes/sentidos-donascer/assets/pdf/controversias/Episiotomia.pdf>. Acesso em: 15 nov. 2016.

et al. Violência obstétrica é violência contra a mulher: mulheres em luta pela abolição da violência obstétrica 1 ed. São Paulo: Parto do princípio; Espírito Santo: Fórum de Mulheres do Espírito Santo, 2014b. Disponível em:

$<$ http://www.sentidosdonascer.org/wordpress/wp-content/themes/sentidos-donascer/assets/pdf/controversias/Violencia-obstetrica-e-violencia-contra-a-mulher.pdf>. Acesso em: 15 nov. 2016.

LEPARGNEUR, Hubert. Força e fraqueza dos princípios da bioética. Bioética - v.4, $\mathrm{n}^{0} 2$, Brasília, Conselho Federal de Medicina, 1996.

LOCH, Jussara de Azambuja. Princípios da Bioética. In: KIPPER, Délio José. Uma Introdução à Bioética. Temas de Pediatria Nestlé, n.73, 2002. p. 12-19

MARIANI, Adriana Cristina; NASCIMENTO NETO, José Osório. Violência obstétrica como violência de gênero e violência institucionalizada: breves considerações a partir dos direitos humanos e do respeito às mulheres. Cad. Esc. Dir. Rel. Int. (UNIBRASIL), CuritibaPR, vol. 2, $\mathrm{n}^{\mathrm{o}}$ 25, jul/dez 2016, p. 48-60. Disponível em: < http://revistas.unibrasil.com.br/cadernosdireito/index.php/direito/

article/viewFile/865/822>. Acesso em: 29 nov. 2016.

MATTOS, Delmo; RAMOS, Edith; VELOSO, Roberto. Entre a autonomia da vontade kantiana e o princípio da autonomia de Beauchamp e Childress: uma discussão acerca da autonomia e da dignidade humana na Bioética e no Direito. Perspectiva Filosófica, Vol. 42, no 1, 2015, ISSN: 23579986.

ORGANIZAÇÃO MUNDIAL DA SAÚDE (OMS). Tecnologia apropriada para partos e nascimentos. Recomendações da Organização Mundial 1996.de Saúde. Maternidade Segura. Assistência ao parto normal: um guia prático. Genebra: 1996.

PAES, Fabiana Dal'Mas Rocha. Estado tem o dever de prevenir e punir a violência obstétrica. 2015. Disponível em: <http://www.conjur.com.br/2015-dez-07/mp-debate-estadodever-dever-prevenir-punir-violencia-obstetrica>. Acesso em: 10 dez. 2015.

PREVIATTI, Jaqueline Fátima; SOUZA, Kleyde Ventura de. Episiotomia: em foco a visão das mulheres. Revista Brasileira de Enfermagem, Brasília, v. 60, n. 2, p. 197-201, mar./abr.

Revista Brasileira de Direitos e Garantias Fundamentais | e-ISSN: 2526-0111 | Maranhão | v. 3 | n. 2 | p. 42 - 65 | Jul/Dez. 2017. 
2007. Disponível em: <http://www.scielo.br/pdf/reben/v60n2/a12v60n2.pdf > . Acesso em: 10 dez. 2015.

SÃO PAULO. Defensoria Pública do Estado de São Paulo. Violência obstétrica: você sabe o que é?. Escola da Defensoria Pública do Estado: São Paulo, 2013. Disponível em: <http://www.defensoria.sp.gov.br/dpesp/repositorio/41/violencia\%20

obstetrica.pdf>. Acesso em: 10 dez. 2015.

SARLET, Ingo Wolfgang. Dignidade da pessoa humana e direitos fundamentais na Constituição Federal de 1988. Porto Alegre: Livraria do Advogado, 2001.

SARLET, Ingo Wolfgang; MARINONI, Luiz Guilherme; MITIDIERO, Daniel. Direitos Fundamentais em espécie. In: Curso de Direitos Constitucional. São Paulo: Revista dos Tribunais, 2012. p. 609-611.

SANTOS, Jaqueline de Oliveira; SHIMO, Antonieta Keiko Kakuda. Prática rotineira da episiotomia refletindo a desigualdade de poder entre profissionais de saúde e mulheres. Esc Anna Nery Rev Enferm 2008 dez; 12 (4): 645-50.

SCHRAIBER, Lilia Blima. O médico e suas interações: a crise dos vínculos de confiança. São Paulo: Hucitec, 2008.

No encontro da técnica com a ética: o exercício de julgar e decidir no cotidiano do trabalho em medicina. Interface - Comunic., Saude, Educ., v.1, n.1, p.123-40, 1997.

SILVA, Artenira da Silva e. Personalidades REconstruídas em aula de aula: um olhar psicológico sobre o ensino médico. 1. ed. São Luís: SENAC, 2005. v. 1. 126p

SOUZA, Karina Junqueira de. Violência institucional na atenção obstétrica: proposta de modelo preditivo para depressão pós-parto. 2014. 106 f. Dissertação (Mestrado em Saúde Coletiva) - Pós-Graduação em Saúde Coletiva, Universidade de Brasília, Brasília, 2014.

UGARTE, Odile Nogueira; ACIOLY, Marcus André. O princípio da autonomia no Brasil: discutir é preciso... Rev. Col. Bras. Cir. 2014; 41(5): 274-277. DOI: 10.1590/010069912014005013.

VENEZUELA. Ley Orgánica sobre el derecho de las mujeres a una vida libre de violência. Março, 2007. Disponível em: < http://venezuela.unfpa.org/sites/lac.unfpa. org/files/pub-pdf/Ley_mujer\%20(1)_0.pdf>. Acesso em: 16 mar. 2016.

VENTURI G; GODINHO T. Mulheres brasileiras e gênero nos espaços público e privado. São Paulo: Sesc/Fundação Perseu Abramo; 2010. Disponível em: < http://www.apublica.org/wp- 
content/uploads/2013/03/www.fpa_.org_.br_sites_default_files_pesquisaintegra.pdf>. Acesso em: 02 nov. 2015.

ZANETTI, Miriam Raquel Diniz et al. Episiotomia: revendo conceitos. Femina, Rio de Janeiro, v. 37, n. 7, p. 367-371, jul. 2009. Disponível em:

<http://www.febrasgo.org.br/site/wp-content/uploads/2013/05/feminav37n7p367-71.pdf>. Acesso em: 16 mar. 2015

WANSSA, Maria do Carmo Demasi. Autonomia versus beneficência. Rev. Bioét (Impr.) 2011; 19(1): 105-17.

WOLFF, Leila Regina; WALDOW, Vera Regina. Violência consentida: mulheres em trabalho de parto e parto. Saúde Soc. São Paulo, v.17, n.3, p.138-151, 2008. 